\title{
The EURANOS cooperative framework for preparedness and management strategies of the long-term consequences of a radiological event
}

\author{
G.H. DUBREUIL ${ }^{1}$, S. BAUDÉ ${ }^{1}$, J. LOCHARD ${ }^{2}$, H. OLLAGNON ${ }^{3}$, A. LILAND ${ }^{4}$
}

ABSTRACT Experience following the Chernobyl accident in the CIS and the EU has clearly demonstrated that policies and strategies for long-term management of extensive contaminated areas must give due importance to social, cultural, ethical, environmental, economic and political factors beyond the sole radiological protection and health perspective. What is at stake in the long-term response to such a situation is the sustainable rehabilitation of living conditions in affected territories, in a context in which each person can actively contribute to his own protection. Preparing or developing rehabilitation of living conditions in a territory affected by long-lasting radioactive contamination is a broader issue of governance as it must address all affected dimensions and articulate the actions of the various concerned actors at the local, regional and national level. To respond to this challenge, a specific research project was implemented by Mutadis, CEPN, NRPA and AgroParisTech from April 2004 to June 2009 in the framework of the EURANOS integrated programme. The overall objective of this project was "to develop a strategic and methodological framework that can inform or assist national authorities in Europe in establishing arrangements for the long-term management and the sustainable rehabilitation of living conditions in extensive areas that may be contaminated as a result of an accident or malevolent act involving radioactive material". The proposed framework describes a two-steps method allowing national and local authorities together with key stakeholders to establish arrangements and preparation strategies in the perspective of long-term management of a radiological event. It may also be used to develop rehabilitation strategies in countries affected by long-lasting radioactive contamination. This framework aims to set up favourable conditions for stakeholders (in particular local communities) to engage effectively and sustainably in the cooperative development of post-accident preparation or management strategies. The first step of the method aims to frame the issue and identify conditions for stakeholders to engage in rehabilitation preparedness or management strategies. The second step aims to develop a local-national cooperation platform gathering local and national, private and public actors to develop together preparation or management strategies.

Mutadis 3, rue de la Fidélité, 75010 Paris, France.

Centre d'Étude sur l'évaluation de la Protection dans le domaine nucléaire (CEPN), 28, rue de la Redoute, 92260 Fontenayaux-Roses, France.

AgroParisTech, 16 rue Claude Bernard, 75231 Paris Cedex 05, France.

4 Norwegian Radiation Protection Authority (NRPA), PO Box 55, No-1332 Østerås, Norway. 


\section{Introduction}

The need to develop policies and widely applicable arrangements for the long term management and rehabilitation of potentially contaminated areas is now broadly recognised among radiation protection organisations, even more since September 11 th, 2001.

International experience, notably in the countries most affected by the Chernobyl accident, has demonstrated that the long term response to a situation of long-lasting radioactive contamination of a territory is not a narrow radiological issue that can be dealt with solely by technical means. It is rather a complex issue, in which various interrelated dimensions of life in the concerned territory are affected (health, environment, economy, food, culture, societal and political relations between the concerned actors...). What is at stake in the long-term response to such a situation is the sustainable rehabilitation of living conditions in affected territories, in a context in which each person can actively contribute to his own protection.

As a consequence, addressing the issue of the rehabilitation of living conditions represents a specific challenge to public authorities and technical support organisations. Classical approaches relying on planning, regulations, standards, and optimisation do not allow efficiently addressing the high degree of complexity of this issue. Therefore, developing and preparing rehabilitation of living conditions in a territory affected by long-lasting radioactive contamination is a broader issue of governance ${ }^{5}$ which must address all affected dimensions and articulate the actions of the various concerned actors at the local, regional and national level. Some legal texts, such as the Aarhus Convention (1998), support this new dimension of governance. They establish legal obligations regarding the right to information and participation of civil society in environmental decision.

To meet this challenge, a specific research project was implemented from April 2004 in the framework of the EURANOS integrated programme. The overall objective of this project was "to develop a strategic and methodological framework that can inform or assist national authorities in Europe in establishing arrangements for the long-term management and the sustainable rehabilitation of living conditions in extensive areas that may be contaminated as a result of an accident or malevolent act involving radioactive material”. The activity named

\footnotetext{
5 "Governance is a more encompassing phenomenon than government. It embraces governmental institutions, but it also subsumes informal, non-governmental mechanisms whereby those persons and organisations within its purview move ahead, satisfy their needs, and fulfil their wants" (in Rosenau (J.) et Czempiel (E-O.) (éd.), Governance Without Government: Order and Change in World Politics, New York, Cambridge University Press, 1992.)
} 
"Preparedness to Post-Accident Rehabilitation" (CAT3RTD01 - PREPARE) ${ }^{6}$ was carried out between April 2004 and June 2009 to develop the framework presented in this article.

The proposed framework consists of a procedure which helps national and local authorities to establish, together with key stakeholders, arrangements and strategies to develop preparedness to respond to the long-term consequences of a possible radiological event. This framework provides public and private actors at local, regional, national and European levels with methodologies to:

- Create the conditions for them to address the issue of long term rehabilitation following a situation of long-lasting radioactive contamination, in relation with their own context and concerns;

- Develop means and tools for rehabilitation strategies adapted to their context;

- Foster innovation and experimentation at territorial and national levels.

This framework may also be used to develop strategies for long-term management in countries actually affected by long-lasting radioactive contamination.

The proposed procedure includes two different steps. The first one aims to frame the issue of rehabilitation of living conditions in territories affected by a long-lasting contamination with a group of stakeholders including key concerned public and private actors at the territorial and national level. It also aims to assess the conditions and means for these stakeholders to engage in the development of preparedness or management strategies in a sustainable way. The second step consists in the development of territorial projects and the setting up of a local and national cooperation platform allowing all types of concerned actors to develop together sustainable preparedness or management strategies.

The first part of this article introduces and briefly describes the methodology used to develop and test the EURANOS PREPARE framework. The two steps of the framework are then presented. Finally, the conclusions draw out the lessons learnt through this process, in particular key conditions identified for local actors to engage in post-emergency preparedness and management issues.

\section{Methodology of the PREPARE project}

In order to implement the PREPARE project and to elaborate a strategic framework for sustainable rehabilitation strategies, the European Commission has

\footnotetext{
${ }^{6}$ This activity was developed by Mutadis, the Nuclear Evaluation Protection Centre (CEPN), the National Institute of Agronomy of Paris-Grignon (now included into AgroParisTech Institute) and the Norwegian Radiation Protection Authority (NRPA).
} 
mandated a core group composed of experts from four institutions having developed specific experiences and skills in the field of post-emergency management and sustainable rehabilitation of living conditions in contaminated territories.

This core group gathered conclusions from different European sources of expertise on the management of the fallouts of the Chernobyl accident in Eastern (Belarus) and Western (Norway) Europe.

The process developed took into account the following characteristics:

- A situation of long-lasting radioactive contamination on a territory necessarily implies deep renegotiation of individual and social values and bonds (after the radiological event). This change should be prepared before a nuclear event would happen.

- Responding to such a situation necessitates not only adequate legal and institutional frameworks and preparedness of public authorities and technical support organisations. It also requires resilience capacities at the territory level. This notably includes capacities of local actors (including private ones) to assess the situation (regarding their own stakes and activities and regarding the local community as a whole), to develop their own response and to negotiate common strategies with the other actors at the local, regional and national levels.

- Preparedness to post-accident situation supposes developing new types of partnerships between stakeholders (especially at the local level) and public authorities involved in emergency and post-emergency management.

- Each national context is specific although involving international and crossborder dimension. Rehabilitation preparedness and management should therefore be addressed country by country.

In order to take into account these characteristics, the framework developed and tested in the PREPARE project was prepared in cooperation with territorial and national stakeholders. In the process, public authorities and experts were on equal standing with other stakeholders. The starting point for the process has been an analysis (co-expertise), at the national level, of the conditions and means for sustainable rehabilitation of living conditions, carried out with a pluralistic group of national and territorial stakeholders (national authorities and experts, local governments and administrations, local professionals, NGOs...). This co-expertise process has been tested in France during the first phase of the EURANOS project (2004-2006). Feasibility of such a co-expertise process at national level was then confirmed in the Norwegian context during the second phase of the EURANOS project (2007-2009). 
At the end of the first phase of EURANOS, the two-steps framework presented in this article was proposed as a tool for public authorities and technical support organisations to develop preparedness or management strategies for the long-term consequences of a radiological event in partnership with stakeholders at the territorial and national level. This framework was grounded on the results of the post-Chernobyl experience in European and CIS countries and on the results of the co-expertise developed in France during the first phase of the EURANOS project.

During the second phase of the EURANOS project, conditions and means for territorial stakeholders to engage in concrete preparedness projects at the territorial and national levels were explored in the French context. In order to do so, the expert group of the EURANOS PREPARE activity provided methodological and technical support to territorial stakeholders who wished to develop preparedness projects.

\section{First step of the EURANOS PREPARE framework: framing the issue and identifying conditions for engaging in rehabilitation preparedness or management strategies}

The first step of the proposed framework allows framing (or reframing) the issue of preparedness or management of the response to a situation of long-lasting radioactive contamination together with a group of stakeholders representing the diversity of concerned actors (private and public, local, regional and national actors, including public authorities and technical support organisations). This step relies on a structured dialogue methodology implemented by a facilitation team independent from public authorities and technical support organisations.

During this step, the stakeholder group elaborates a national analysis of the consequences of a contamination event within the existing national context, and of the conditions required for the cooperative development of preparedness or management strategies. More specifically, the objectives are the following:

- identifying and recognizing the complexity of a situation resulting from the radioactive contamination of a territory;

- identifying the dispatching of responsibilities between local, national and European levels and the fields of shared responsibility;

- assessing the capacities of local communities to address the complexity of a situation of radioactive contamination;

- identifying key issues to be addressed in rehabilitation preparedness (or management) strategies;

- identifying the conditions (including ethical conditions) for stakeholders to engage in preparedness (or management) strategies; 
- negotiating principles for the development of joint actions by the various concerned actors;

- elaborating first action proposals.

The stakeholder group should gather actors directly concerned with the development and implementation of public policy on post-accident rehabilitation issues. Special attention should be paid to achieve the diversity needed to appropriately represent all potential stakeholders. The group may include national authorities and administrations concerned with the issue of long-term management of a post-accident situation (e.g. nuclear safety and radiation protection authorities, health administration, food administration...), technical support organisations, NGOs having engaged a reflection on technological risks including or not the risk of a nuclear accident and local communities and other concerned actors. The local communities involved should represent different categories with respect to the vulnerability to radiological contamination. They may include communities neighbouring nuclear facilities as well as other communities having a particular concern on radiological risks due to the nature of their activities (e.g. food production) or of their perspectives of sustainable development (e.g. nuclear free local communities in UK). The choice of stakeholders representing local communities should be made in such a way that the different categories of concerned local actors (local elected representatives, local administrations directly concerned, local professionals, local NGOs...) are represented.

Participation in the stakeholder group should be understood as a partnership set up on a free and voluntary basis. Beyond the performance of an analysis, the first step is also pursuing the objective of creating conditions for local stakeholders to become sustainable and autonomous partners in the development of preparedness or management strategies and policies in the long term. It is expected as an outcome of this step that some members of this stakeholder group would candidate for engaging in preparedness activities (or response activities in the case of an actual situation of radiological contamination). This willingness of members of the stakeholder group to engage themselves further in the development of preparedness or management strategies is a success criterion.

The core of this first step is the organisation of co-expertise workshops. In the perspective of the specific objectives of this step, and to allow a constructive and free dialogue between the various categories of stakeholders, the co-expertise seminars use a structured dialogue methodology, the IDPA method (see below). The implementation of the IDPA method in the French and Norwegian context was preceded by field visits of the French and Norwegian stakeholder groups in a Norwegian region still affected by contamination from the Chernobyl accident (Nord-Trøndelag). 
The IDPA method is a structured multi-stakeholder dialogue method developed by AGROPARISTECH ${ }^{7}$ to address complex issues. It is a co-expertise method: each participant is considered both as an expert of his own situation, territory, technical field... and as an expert of the whole strategic issue addressed during the process. The IDPA method allows integrating the different forms of expertise held by the participants (scientific and technical expertise, expert knowledge of the territory, local stakes and habits held by the territorial actors, strategic expertise...). The pluralistic stakeholder group mobilised during this process does not have to be representative of the concerned stakeholders from a sociological or statistical point of view. However, it has to achieve sufficient "strategic representativeness", which means that it has to include different types of stakeholders and gather sufficient diversity of points of view on the issue addressed. This procedure aims to identify the elements of analysis and action proposals that can be shared between the various participating stakeholders. It does not aim at "mapping" the different stakeholders' opinions and positions.

This pluralistic co-expertise process is organised using a standard procedure described further down. It involves a professional ethics of free, secure and constructive participation. This includes an explicit agreement between the participants and the facilitators, which implies the following commitment of the facilitation team: voluntary participation, equal footing of the participants and equal opportunities to express, neutrality of the facilitation team regarding the issue at stake, guarantee that the process will not be taken over by one participant or a sub-group, traceability of the content of the participants' interventions (without mention of the speaker), feedback of a synthesis of the debates to the participants and validation by them.

The facilitation team mobilised consists in at least two persons: one person who moderates the discussion and leads the process and one person who writes down the ideas (or the expertise) expressed by the participants.

The issue to be addressed is explicitly formulated at the beginning of the process. In the present case, the issue addressed by the stakeholder groups in France and in Norway was "the conditions and means of long-term rehabilitation of living conditions on French or European territories susceptible to be contaminated by a radiological pollution (de facto situation)". The strategic analysis carried out by the stakeholder group is structured by the IDPA method of analysis according to the four following strategic topics:

- identification of the situation, actor, problems and strategic core of the addressed issue;

\footnotetext{
${ }^{7}$ Within the Institute for Patrimonial Strategies in AgroParisTech, headed by Professor Henry Ollagnon.
} 
- diagnosis of the actions engaged by the different actors individually and by the system of actors as a whole;

- prospective evolution of the situation, problems, and actions (relevant space and time scales, negative, positive and underlying scenario, main stakes, threats and assets);

- action proposals (objectives, needs, actions, process of change, governance framework, success criteria).

These four topics are addressed successively by the stakeholder group during one or two workshops (two days in total are necessary to go through the four topics with a stakeholder group of about 20 people). For each topic, two rounds of discussion are organised. At first, all participants are invited to express themselves in both the perspective of their specific field of expertise and action and in the perspective of the global strategic situation. Then, each participant is invited to react to what was expressed by the group. The contributions of all participants are handwritten by the facilitation team on a medium visible to all (e.g. paperboard), without mentioning their author.

After these workshops, a synthesis of the strategic analysis made by the group is prepared by the facilitation team (without reference to authors of the elements of expertise which are integrated) and circulated among the participants. This synthesis is then presented, discussed and validated by the pluralistic group during a final workshop. This workshop is also an opportunity to discuss further steps to be taken (in particular the conditions and means for the development of the second step of the framework).

Experience of the implementation of this co-expertise process in Norway during the second phase of the EURANOS project has shown that such guidance can be adapted to national context and specificities, insofar as the ethical basis of the method is respected and the four topics are addressed.

Implementing the first step of the EURANOS PREPARE framework in a given country allows entering in the development of preparedness or management strategies (second step of the process) on the basis of a shared framing of the issue of preparedness or management of long-term consequences of a long-lasting radioactive pollution. This facilitates the engagement of stakeholders beyond public authorities and technical support organisations (e.g. local communities, NGOs and their federations and associations at the national level, private businesses that could be impacted by radioactive contamination, professional associations and technical institutes, universities...). Moreover, the propositions of actions and the governance arrangements that arise from the strategic analysis carried out during the first step constitute a first basis for developing preparedness or management actions on a cooperative basis. 


\section{Second step: setting up a local-national cooperation platform}

During the first step, participants in the stakeholder group have developed a shared understanding of the fundamental issues at stake in the long-term response to a situation of long-lasting radioactive contamination of a territory. They have also identified conditions to engage in a cooperative approach for post-accident management or preparedness.

The second step of the PREPARE framework aims to set up favourable conditions for stakeholders (in particular local communities) to engage effectively and sustainably in the cooperative development of post-accident preparation or management strategies.

This second step responds to two particular challenges in the issue of preparedness and management of situations of long-lasting radioactive contamination. At first, preparedness and response necessitate not only adequate legal and institutional frameworks and adequate preparedness of public authorities and technical support organisations. It is also a matter of developing resilience capacities at the territory level. This notably involves capacities of local actors (including private ones) to assess a situation of long-lasting radioactive contamination (as regards their own stakes and activities and as regards the local community as a whole), to develop their own actions and to negotiate common strategies with the other actors at the local, regional and national levels. The second challenge addressed is the sustainability of the engagement of stakeholders which arise from the continuous and long-term character of processes of both preparedness and response to situations of long-lasting radioactive contamination. A key condition for avoiding "stakeholder fatigue" and favour sustainable engagement of stakeholders (in particular local ones) is to safeguard their autonomy in the process.

The second step of the proposed framework includes two different parts. The first one aims to preparing the conditions for local or regional actors to autonomously engage in a cooperative process with public authorities and experts. It involves the development of initiatives at the territorial level in order to facilitate the development of a contextualised assessment of the stakes and opportunities linked to post-emergency issues and the development of local competences in this field. In the French context, from 2006 to 2009, several territorial initiatives on post-accident issues were developed in Montbéliard, Golfech and Saclay. In addition, the ANCLI (National Association of Local Liaison Committees attached to the French nuclear sites) set up an inter-territorial working group on postemergency issues in 2007. All these initiatives were supported by EURANOS PREPARE experts in the framework of the project. 
The second part of this step is the setting up of a local-national cooperation platform, once the conditions for sustainable engagement of local actors are met. This platform is a tool to develop a cooperative process of framing of post-accident preparedness or management strategies.

The first part of this second step consists in the development of concrete projects to improve preparedness of local communities in the perspective of the response to a radiological event. These projects may involve partnerships between local communities and public organisations responsible of the development and/or implementation of rehabilitation strategies.

Except in actual situations of radioactive contamination, it is uneasy for local actors to invest significant resources on solely post-emergency issues. In a preparedness perspective, it is easier for local actors to consider post-emergency issues within a multi-risk perspective and therefore to include radiological as well as chemical, biological and natural risks in their preparedness processes. Moreover, a multi-risk approach is justified by the existence of transversal issues crossing different types of risks and contexts (e.g. public health in the context of a deterioration of sanitary conditions).

Local communities and actors most often need technical and/or methodological support to develop initiatives in the field of preparedness (or management) of response to long-lasting radioactive contamination. This can be achieved through partnerships with public authorities and technical support organisations or with other technical organisations (e.g. universities, independent scientific and technical institutes...). A condition of sustainability of the engagement of local stakeholders in such partnerships is their degree of ownership of the developed projects. In particular, the projects developed by local communities and actors in partnership with public authorities should be related to clearly identified concerns and stakes of the engaged actors in their specific territorial context (e.g. vulnerability of key activities to radioactive contamination, particular concerns of the local community as regards radiological risks, fulfilment of legal preparedness obligations...).

The second part of this step of the EURANOS PREPARE framework is the development of a coordination platform gathering territorial and national actors involved in concrete local projects. This platform is complementary to the development of initiatives at the territorial level. It aims at:

- identifying transversal issues among the different territorial co-operative actions and initiatives;

- facilitating the emergence of a critical pluralistic group of local, regional and national actors working on rehabilitation preparedness; 
- ensuring an adequate connection between the existing regulatory framework and management tools of public authorities, and the initiatives taken at the local level;

- developing recommendations for national public authorities for developing or updating technical, institutional and regulatory frameworks for rehabilitation, articulating public (e.g. national, regional and local authorities) and territorial spheres of action (local actors, including elected representatives, NGOs, local professionals, companies, ...).

The local-national platform relies on a pluralistic group of stakeholders, which notably includes the participants of the first step of the framework who would renew their engagement. The stakeholder group for this work may include:

- local communities interested in emergency management and rehabilitation strategies in a multi-risk perspective (elected representatives, local and regional administrations, local professionals, local NGOs...);

- associations or networks of local communities and actors;

- central and decentralised State administrations;

- technical support organisations;

- other scientific and technical organisations;

- operators;

- private businesses and professional organisations in sectors of activities that could be impacted by a situation of long-lasting radioactive contamination;

- network of local actors concerned with nuclear issues;

- NGOs.

In order to facilitate sustainable engagement of private and territorial stakeholders, the governance structures of this platform should be carefully designed to allow all types of actors to effectively influence the agenda and operation of the platform and to avoid domination of any particular type of actor. One particular way of developing shared ownership of the platform among the stakeholders is to give the opportunity to all engaging stakeholders to contribute to the definition of the objectives, the governance structure and the decision procedures of the platform before its creation.

The work programme of the local-national cooperation platform should be structured on objectives of common interest defined together by the participants. It could include the following objectives:

- discussing and assessing the experience of actual cases of contamination (radiological, chemical or other type of contamination), possibly including foreign cases;

- developing awareness of the tools developed at the territory level by local actors in the field of risk management; 
- assessing the feedback experience of positive projects of local communities that contribute to develop territorial resilience, in particular the projects involving partnerships with national actors participating to the local-national cooperation platform;

- benchmarking good practices with other national processes of development of rehabilitation preparedness strategies taking place in other countries.

The operation of the local-national cooperation platform and the engagement of local and national stakeholders may be facilitated by the intervention of a methodological task force providing structured dialogue methodology and moderating discussions.

However, the development of cooperative relations of work between the participants to the platform does not necessarily imply the absence of criticism or even conflicts. On the contrary, the quality of preparedness and management of situations of long-lasting radioactive contamination is reinforced through the establishment of a critical dialogue between participants.

A key condition for the sustainability of the process is the creation of balanced relations between the participants and the capacity of stakeholders that are not in an influential position (in particular local stakeholders) to progressively develop their skills in the post-emergency field and effectively influence the decisions taken by the other actors (in particular public authorities). The operation of the platform should therefore include a reflexive assessment of the process in progress and its methodology as well as regular feedback. In particular, the process should give opportunities to the engaged stakeholders to evaluate how the process contributes (or not) to increasing their actual influence on decisions that impact them.

\section{Conclusions}

Significant improvements, especially in Europe have been made to emergency and post-emergency preparedness management in recent years. They include advances in decision support tools, improved methods for information and data exchange and more inclusive processes involving stakeholders in evaluating and revising emergency arrangements.

Regarding the issue of preparedness to rehabilitation of living conditions on the mid- and long term in a post-accident context, we stand now in Europe at the beginning of a process of change in the long run, in which new types of relations of partnerships are progressively built between public authorities, traditional 
emergency and post-emergency manager and local communities and stakeholders. This process articulates two complementary directions.

- Progressive evolution of the processes of construction of public policies and tools (e.g. plans, technical tools, legal and regulatory frameworks...) towards increased possibilities for local actors and stakeholders to engage in policy and decision framing at regional and/or national levels. A more specific trend is the gradual opening of public expert institutions to societal engagement practices in order to meet societal demands for reliable, unbiased and transparent information and an active role of citizens in the construction of knowledge, in particular in the field of risks and environmental issues.

- Gradual empowerment of local communities and territorial stakeholders, which progressively develop autonomous reflections on post-accident issues through territorial projects that may articulate post-accident preparedness in a multi-risk approach (e.g. radon, chemical risks...). This empowerment may be facilitated by the mobilisation of existing networks of territorial actors (e.g. the ANCLI in the French context or EUROCLI network at the European level) or the emergence of new networks. Such networks may, on the one hand, support the development of experimental projects by territorial actors. On the other hand, it may help local actors developing a structured and influential position at the regional and national level and becoming full-fledged partners in the development of post-accident preparedness strategies. Another key factor of empowerment is the availability of technical mediation to help non-expert actors to develop their competences to address and investigate technical issues from their own point of view.

The two steps of the EURANOS PREPARE framework aim to facilitate the development of these two trends of evolution and to fruitfully articulate them by drawing lessons from experimental territorial projects to frame and/or adapt the regulations and tools developed by public authorities in the post-accident field. A key challenge for public authorities and technical support organisations is to support the initiatives of territorial actors while preserving their autonomy. This requires negotiating new relationships with the other concerned stakeholders (notably local governments and local actors), based on a balanced partnership approach.

The proposed framework aims at producing reliable knowledge related to sensible strategies and management actions and at creating the conditions for the concerned stakeholders (including local actors) to become autonomous and fullfledged democratic players in the longer term. Therefore, an important distinction has to be made between the process that is proposed in our Framework and forms of passive stakeholder participation or involvement which mainly aim to improve the knowledge basis of decision makers (who are themselves expected to produce 
change). In our context, the growing influence of concerned local actors is expected to create the conditions for addressing the complexity of preparedness or management of the long-term response to a radioactive contamination event.

This process involves in particular an evolution of the roles played by experts and of their relations with the public. In particular, addressing scientific and technical aspects of post-accident issues with civil society actors requires technical mediation in order to establish meaningful and fruitful interfaces between the public and technical issues and problems and to help non-expert actors to develop their competences to address and investigate technical issues. Technical mediation may be provided by technical support organisations, universities, research centres and other technical organisations. It may notably resort to tools for informing discussions, debates and deliberations (TIDDDs) ${ }^{8}$.

The proposed framework also includes a self-assessment dimension insofar as the engaged actors build their own evaluation of the situation at stake and the associated governance framework. As the process of cooperative development of preparedness or management strategies progresses, the engaged actors reframe the issues at stake while appropriating and connecting them with their own stakes and, for local actors, with an integrated territorial perspective. They also develop their own assessment of the cooperative process they take part in.

The EURANOS PREPARE framework includes a strategic dimension which is of primary importance. Through the implementation of this framework, stakeholders (in particular local actors) are empowered so that they become active and autonomous players in a continuous process of evolution of the governance framework for the development of preparedness or management strategies for the long term response to a situation of radioactive contamination. In this regard, it should be noted that the EURANOS PREPARE framework is rather an incubator for developing (and regularly updating) an adapted governance framework for preparedness and management than a part of this very governance framework. This strategic dimension also requires experts for methodological facilitation supported by professional standards. Professional inputs in this process, in terms of effectiveness, efficiency, fairness and competency, appear to be a key factor for enabling actual influence of local actors on decision-making processes.

The PREPARE framework has been successfully tested in France and in Norway (step 1 of the framework). In Europe, beyond the PREPARE activity,

\footnotetext{
8 This formulation comes, notably, from the works of Silvio Funtowicz and Jerome Ravetz, who have led the emergence of the perspective of a "post-normal" practice of science, see S. Funtowicz \& J. Ravetz, "A New Scientific Methodology for Global Environmental Issues" (1991), "Science in the Post-Normal Age" (1993), "Emergent Complex systems" (1994) and "The Worth of a Songbird" (1994).
} 
several initiatives involving cooperation between national authorities or technical support organisations were developed, notably in Finland (cooperation with stakeholders to address contamination issues in the fields of food production, fuel peat production and forest industry), in the United Kingdom (development of a framework for recovery at national, regional and local level), in Spain (Development and test of a tool for long-term management of contaminated lakes, rivers and catchments) and in Slovakia (stakeholder involvement in development and design of emergency preparedness routines).

Further development of post-accident preparedness in Europe will necessitate exchanges of experience between these initiatives and the projects developed in the French and Norwegian context. In order to structure this dialogue, it will be necessary not only to develop multi-stakeholder dialogue and cooperation platforms at the local and national level but also at the European level in order to build a shared understanding of post-accident issues and stakes.

Acknowledgment. This work has received partial financial support from the European Commission Sixth Framework Programme (Nuclear Fission/Radiation Protection) under the EURANOS integrated project: European approach to nuclear and radiological emergency management and rehabilitation strategies (Contract No: FI6R-CT-2004-508843). 